\title{
Dealing with emergencies in rural areas of Europe: proceedings from WONCA Europe 2000
}

\author{
J Gillies, C Lionis, J MacDonald, C Laird, J Szabo, B Nunes, L Burriel, H Lund, C Made
}

\begin{abstract}
On 4 July 2000, two workshops on handling emergencies in rural areas of Europe were held at the WONCA (World Organisation of National Colleges and Academies of Family Medicine/General Practice) conference in Vienna under the auspices of EURIPA (European Rural and Isolated Practitioners' Association). Papers submitted covered varying patterns of service provision and examples of short intensive training for emergencies at resident and general practitioner levels. Ways of collecting data routinely for accident prevention were also discussed. The workshops concluded that there was a need for more research in the application of emergency skills, that lack of confidence in dealing with emergencies may contribute to recruitment problems, and that further work towards a document detailing training requirements for emergencies was needed. This will be developed at a EURIPA workshop at WONCA in Tampere, June 2001.

(Emerg Med f 2001;18:305-307)
\end{abstract}

Keywords: emergency care; trauma; training; general practice; rural

On 4 July 2000, two workshops on handling emergencies in rural areas of Europe were held at the WONCA conference in Vienna. The aims of the workshops were to discuss present arrangements for the organisation of emergency care, training for GPs in emergency and trauma care, to look at current service provision in some countries, and to consider aspects of epidemiology and prevention.

There is little literature on this subject. The WONCA document "Policy on Training for Rural Practice"1 discusses the need for training for advanced rural practice skills, including emergencies. Problems with both training and service provision are internationally recognised. ${ }^{2}{ }^{3}$ Lack of confidence in dealing with emergencies is a factor deterring young doctors from taking up posts in rural areas. ${ }^{4}$

The workshops were organised by EURIPA

A list of authors and affiliations is shown at the end of the article.

Correspondence to: Dr Gillies, Selkirk Medical Practice, Viewfield Lane, Selkirk TD7 4LL, Scotland (j.gillies@

selkirk.borders.Scot.nhs.uk)

Accepted for publication 3 April 2001
(RTAs) reached 8000 per annum, many preventable by good resuscitation. BASICs schemes established by concerned local GPs spread throughout Scotland in the 1970s. Because Scotland has some of the lowest population densities in Europe, rural GPs are often the first health professionals called to deal with road traffic and farm accidents, obstetric emergencies and medical emergencies. The vision for the future is of a national prehospital care service for rural Scotland.

Such a vision is only achievable through adequate professional training. Dr Colville Laird (GP, Scotland, BASICS Scotland education officer) gave an overview of current training for emergencies for Scottish GPs. Training to deal with such situations was for historical reasons not a priority until BASICS started organising courses in prehospital resuscitation in 1993. These now cover cardiac resuscitation, trauma resuscitation, paediatric emergencies, major incident management and scenario practice, over two and a half days. A more advanced course covers hypothermia, drowning, pain relief, triage and obstetric emergencies. By 1995, Health Service purchasing authorities had starting paying for courses for GPs in some areas, and in 1998, Scotland's chief medical officer stated that they should be available to all rural doctors.

Much evidence for the benefit of this training comes from North America, where patterns of trauma are different (for example, gunshot wounds rather than blunt trauma). Dr Laird highlighted the need for European evidence to inform future training needs and provision.

The recently established Scottish Remote and Rural Areas Resource Initiative (RARARI $)^{5}$ had recognised the need for both training and evidence by supporting training provision for 350 rural GPs in Scotland each year, allied to a research exercise to look at the impact of this investment.

Dr Janos Szabo (Semmelweiss University, Budapest, Hungary) gave a presentation of training for emergencies for resident medical officers in Budapest. An intensive, practically orientated course of one week has been developed, with the aim of giving young doctors the theoretical and practical knowledge to cope with acute and life threatening illnesses and trauma in hospital and general practice. Educational feedback is used to improve the course year on year. Organisation, clinical, ethical and legal aspects are covered. Ninety six hours of practical experience on ambulance or emergency department duty complement the theoretical part of the training. 
Dr Berta Nunes (GP, Portugal) described a study of admissions and transfers from a GP run emergency department. Of 192 cases, 90\% of cases were dealt with by the attending GP. Nine per cent were admitted under GP care, and $10 \%$ transferred on to the district hospital. The transfers included major trauma, women in labour, surgical abdomens and severe respiratory problems. She highlighted the need for more training to deal with major medical emergencies, intra-partum obstetrics, and trauma in rural areas.

Dr Luis Garcia Burriel (GP, Spain) presented a paper on the organisation of primary care to deal with urgent and emergency cases in rural Spain. Each province is divided into "basic health areas", which cover a population of 5-25000 inhabitants. Primary care staff look after their own villages during the day. During the evening and night, a central location in each area is designated to cover emergencies, and is staffed by GPs and nurses from that area in rotation. Standard diagnostic and emergency equipment is available at the centre, and a mobile unit visits cases who are unable to attend. This has been developed over 18 years, and has been found to reduce isolation among GPs, has increased patient satisfaction and led to an improvement in professional opportunities in rural general practice.

Professor Christos Lionis (University of Crete, Greece), in place of Dr Marios Chatsiarsensis presented two epidemiological surveys of accidents in two areas of rural Crete. Minor injures were most common in children at school. Falls from donkeys were a common cause of major trauma in some areas during olive collection, and many injuries were caused by cutting and punching instruments. Foreign tourists were frequently involved in RTAs. Lack of personal safety precautions was a factor in some accidents, according to one study. Lack of rural radiography facilities and lack of adequately trained nursing staff were highlighted as problems reducing quality of care. He discussed the involvement of GPs in the management of accidents, and the organisational issues raised.

Dr Helge Lund (GP/medical officer, Norway) presented data on accident prevention in a small community in the north of Norway. Collaboration between medical and local authorities is essential for local acceptance. This involves a GP electronic database that registers all accidents in the community. Most accidents among children and elderly people take place at home, while sport and leisure accidents are commonest in young people. The data are analysed by working groups for specific areas such as elderly patients, agricultural accidents, traffic accidents and children. They develop initiatives for prevention that are put forward for local action by public health and local government. This local feedback loop from the data to preventive activities works best at a local level, with support form national structures.

Dr Curt Made (GP, Sweden) discussed data from an ongoing survey of snowboarding inju- ries in Lapland. The injury risk for snowboarders was three times higher than that for downhill skiers. Fifty six per cent of injuries were to the upper limb, and wrist injuries were especially common. As snowboarders became more experienced, head and neck injuries became more common. The survey has resulted in the development of a wrist guard to prevent this specific wrist injury to snowboarders.

\section{Discussion}

The workshops and subsequent discussions were of great value in highlighting many important issues in this complex area of practice, and in sharing good practice and necessary actions to move forward training and research.

Much of the literature on this subject comes from North America ${ }^{6}$ or Australia. ${ }^{7}$ While much of this is relevant to European populations, patterns of trauma, geography and doctor distribution in Europe are markedly different, and there is a need for more Europe specific research. Some recent papers suggest that the issue is being tackled. ${ }^{89}$

The training of residents in Hungary and of rural GPs in Scotland were examples of good practice, which could be usefully adapted to other parts of Europe. The studies from Greece, Portugal, Norway and Sweden illustrated the importance of good data collection that informed and shaped local service development and prevention.

Although there were obviously major differences in the geography and in the service needs of different parts of rural Europe, common important issues emerged. These included the following:

- lack of research in the application of emergency skills in rural practice

- training of rural GPs in emergency medicine and trauma is important and sometimes neglected

- training has common elements, but has to be tailored to the needs of the service locally

- a short but intensive training course seems to be effective in rural general practice but further studies are required

- lack of confidence in dealing with emergencies contributes to recruitment problems in rural areas

- building teams to cover emergencies can contribute to reducing isolation, improve GP skills and improve service provision

- gathering local information can help communities take measures to prevent accidents After the workshops, there was a consensus that there was a need to continue discussion in several of these areas at a European level. EURIPA has therefore formed a group of rural GPs to work together to build on the WONCA Policy on Training for Rural Practice, and develop a working document on training for emergencies in rural areas of Europe. This will be further discussed at the workshop "Training for emergencies in rural areas of Europe: how best to do it?" at the forthcoming WONCA conference at Tampere, Finland in June 2001. 
I Gillies, Selkirk Medical Practice, Scotland, UK; C Lionis, Department of Social and Family Medicine, University of Crete, Heraklion, Crete, Greece; J MacDonald, Wigtown Surgery, Newton Stewart, Scotland, UK; C Laird, Auchterarder Heath Centre, Scotland, UK; J Szabo, Department of Family Medicine, University of Semmelweiss, Budapest, Hungary; B Nunes, Alfandega da Fe Health Centre, Alfandega, Portugal; L Burriel, Centro de Salud Santa Maria del Páramo, Leon, Spain H Lund, Os Council, Os, Norway; C Made,Tarnaby Rura Medical Centre, Tarnaby, Sweden.

1 WONCA. Policy for training for rural practice. Hong Kong: WONCA Publications, 1995.

2 James R. Benign neglect of rural health: is positive change on its way? New Zealand Family Physician 1998;26:20-3.

3 Scottish Office Home and Health Department. Health care services in remote and island areas in Scotland. Edinburgh: HMSO Books, 1995:20.
4 Ross S, Gillies JCM. Characteristics and career intentions of Scottish rural and urban GP registrars: cause for concern. Health Bull 1999;57:44-52.

5 Remote and Rural Areas Resource Initiative www.rarari.org.uk)

6 Taylor AS. Emergency medicine: educational objectives for the undifferentiated physician. F Emerg Med 1994;12:25562 .

7 Hoyal FM. Retention of rural doctors. Austr 7 Rural Health 1995;3:2-9.

8 Murphy AW, Bury G, Dowling J. Teaching immediate cardiac care to Irish general practitioners - a faculty based approach. Medical Education 1995;29:154-8.

9 Murphy AW, Bury G, Dowling J, Lynch C. The teaching of Immediate cardiac and trauma care to general practitioners in a skills - based outreach format: an assessment in terms of information gain. Med Educ 1999;33:774-6. 